\title{
Association Between Glutathione S-Transferase (GST) Polymorphisms and Schizophrenia in a Chinese Han Population
}

This article was published in the following Dove Press journal: Neuropsychiatric Disease and Treatment

\author{
Ci Yan (D) ${ }^{\prime}$ \\ Li Duan' \\ Chunfeng Fu' \\ Chunsheng Tian' \\ Bihui Zhang' \\ Xiaojun Shao' \\ Gang Zhu (iD) ${ }^{1,2}$ \\ 'Department of Psychiatry, The First \\ Affiliated Hospital of China Medical \\ University, Shenyang I I000I, People's \\ Republic of China; ${ }^{2}$ Department of \\ Central Laboratory, The First Affiliated \\ Hospital of China Medical University, \\ Shenyang I I000I, People's Republic of \\ China
}

Background: Glutathione S-transferase (GST) is an important antioxidant enzyme in the body. The weakening of the antioxidant system causes damage to the cells and tissues that make up the organism, adversely affects the function of the nervous system, and ultimately leads to schizophrenia (SCZ). Previous studies have yielded inconsistent results across different ethnic populations.

Purpose: This case-control study was carried out to investigate whether genetic polymorphisms in GST could be associated with SCZ in the Chinese Han population.

Patients and Methods: A total of 794 participants, including 379 SCZ patients (case group) and 415 healthy individuals (control group), were genotyped by polymerase chain reaction-restriction fragment length for polymorphisms in GST genes.

Results: The study found that the frequency of the GSTM1 null genotype was higher in case group than control group ( $p=0.003)$. The frequency of the GSTM1 and GSTT1 double null genotype was also higher in case group than control group $(p=0.008)$.

Conclusion: We conclude that the GSTM1 null genotype and the GSTM1 and GSTT1 double null genotype may be related to the onset of SCZ in Chinese Han population.

Keywords: glutathione transferase, gene polymorphisms, schizophrenia

\section{Introduction}

Schizophrenia (SCZ) is a severe and complex mental disease that primarily affects young adults. It is characterized by disorders of perception, thinking, emotion, and behavior, with significant cognitive impairment and social dysfunction. ${ }^{1}$ The costs of this disease to affected individuals, their families, and society are enormous. ${ }^{2}$ The 1-month prevalence of SCZ in the Chinese population is $0.78 \%$, according to an epidemiological survey conducted in four Chinese provinces. ${ }^{3}$ Despite a greater than 100-year history of SCZ research, its pathogenesis is still not fully understood. Numerous studies have demonstrated that genetic background and environmental factors play an important role in the occurrence and development of SCZ. ${ }^{4,5}$

Increasing evidence supports that the pathophysiology of SCZ involves oxidative stress. ${ }^{6,7}$ Abnormal oxidative stress parameters have been reported in blood, cerebrospinal fluid, red blood cells, platelets, and neutrophils in patients with SCZ. ${ }^{8-12}$ Oxidative stress is closely linked to diverse physiological and pathological processes, such as inflammation, mitochondrial dysfunction, oligodendrocyte abnormalities, and the impairment of gamma-aminobutyric acid interneurons. These changes are closely
Correspondence: Gang Zhu Department of Psychiatry, The First Affiliated Hospital of China Medical University, Shenyang II000I, People's Republic of China

$\mathrm{Tel} / \mathrm{Fax}+862483282184$

Email gzhu@cmu.edu.cn 
related to the development of SCZ. ${ }^{13}$ The presence of oxidative stress might serve as a potential biomarker in the cause, development, and clinical course of SCZ. ${ }^{14}$

Glutathione S-transferases (GSTs) are a family of prokaryotic and eukaryotic Phase II metabolic isozymes that provide critical defense against toxicants. ${ }^{15,16}$ GSTs are expressed in many tissues in the human body. Previous studies have reported that GST levels of prefrontal cortex, peripheral blood, and cerebrospinal fluid were decreased in patients with SCZ, and suggested that GSTs play an important role in the development of SCZ. ${ }^{17-23}$

GSTs are grouped as alpha, mu, omega, pi, theta, and zeta classes that are encoded by GSTA, GSTM, GSTO, GSTP, GSTT, and GSTZ genes, respectively. ${ }^{24}$ Among GST genes, GSTM1, GSTT1, and GSTP1 have well-defined single nucleotide polymorphisms (SNPs). ${ }^{25}$ The GSTT1 gene contains two alleles, the functional gene GSTT1+ and the nonfunctional gene GSTT1null. Similarly, the GSTM1 gene contains the functional gene GSTM1+ and the nonfunctional gene GSTM1null. Previous studies reported that the frequencies of these genetic variants vary among human ethnic groups. ${ }^{26}$ The genotype distribution of these variants in the Chinese population is similar to that of the Korean and Japanese populations but different from European, South American, and African populations. ${ }^{27}$ Common homozygous deletion polymorphisms of the GSTT1 and GSTM1 genes, as well as the GSTP1 Ile105 SNP, have been shown to eliminate enzyme activity and increase susceptibility to oxidative stress. ${ }^{26}$ Therefore, the deficiency in GST enzyme activity caused by genetic polymorphisms of GSTM1, GSTP1, and GSTT1 may be a risk factor for developing various diseases, such as glaucoma, chronic obstructive pulmonary disease, psychosis, and cancer. ${ }^{20-23}$

Genes involved in the antioxidant system are associated with increased risk of SCZ. ${ }^{15}$ Up to now, numerous studies have evaluated the association between risk of SCZ and GST gene polymorphisms, but the results were inconsistent. For example, the null genotype of GSTM1 was reported to be associated with SCZ in Japanese; ${ }^{22}$ however, Raffa et al found no association between GSTM1 genotype and SCZ in Tunisians. ${ }^{27}$ Another case-control study showed that a single genotypic change (GSTP1 rs1695, GSTM1 null, or GSTT1 null) was not associated with SCZ, but a combination of different GST SNPs (GSTM1 null/GSTT1+) was related to SCZ. ${ }^{28}$ These discrepancies may be related to sample size and genetic background. To date, few studies have investigated the association of GST SNPs and SCZ in the Chinese Han population. We, therefore, conducted an association analysis to evaluate the roles of GST gene polymorphisms (GSTP1, GSTT1, GSTM1) on susceptibility to SCZ in Han Chinese from a single case-control study.

\section{Materials and Methods \\ Patients and Controls}

The schizophrenic group consisted of 379 individuals (192 male and 187 female) with a mean age of $37.08 \pm 11.06$ years (range: 18-65 years) recruited as inpatients at six hospitals in Liaoning Province. All patients with a diagnosis of SCZ, according to the Diagnostic and Statistical Manual for Mental Disorders (DSM-IV) (American Psychiatric Association, 2004), were confirmed independently by two senior psychiatrists based on a structured interview and medical records. Exclusion criteria were as follows: any organic brain disorder, mental retardation, or additional physical or psychiatric disorders. Healthy controls consisted of 415 individuals (213 male and 202 female) with a mean age of $36.29 \pm 9.60$ years (range: 18-65 years) recruited from the same geographic area as the patients. Exclusion criteria were as follows: any psychiatric disorder or serious physical illness.

\section{Principles of Ethical Review}

This research was based on the Declaration of Helsinki as the moral principle. All participants were informed of the purpose, experimental methods, benefits and risks of the experiment, and the rights of the participants during the experiment. A written consent was obtained from all participants after a full explanation of the study. The study was approved by the Ethics Committee of China Medical University.

\section{Polymorphism Genotyping}

Genomic DNA was extracted from venous blood using standard techniques using DNA extraction kits (Wizard Genomic DNA purification kit, Promega, Beijing, China). The purity and quantity of DNA were estimated by the absorption value in a spectrophotometer. Collected DNA samples were stored at $-20^{\circ} \mathrm{C}$. Polymerase chain reaction (PCR) was used to determine the polymorphisms of GSTT1 (rs4630 and rs11550605) and GSTM1 (rs737497 and rs1065411) genes, and polymerase chain reaction combined with restriction fragment length polymorphism (PCR-RFLP) was used to analyze the GSTP1 (rs1695 and rs4891) gene polymorphisms. Genomic DNA was amplified with the following primer pairs (Table 1). 
Table I Primer Pairs That Amplify Genomic DNA

\begin{tabular}{|l|l|l|}
\hline SNP & Sense & Antisense \\
\hline rs489I & TCGCTGACTACAACCTGC & AAGCCACTGACTGTGCTG \\
rs 1695 & CAATCCTTGCCCTGTG & TTACTTGGCTGGTTGATG \\
rs4630 & GCTGGGAAACCTCACCCTTG & CTCTTGGCAAACATCAGGGGG \\
rs 11550605 & GTGCCCTTCCCTTACCC & GCCCTTCCCTTACCCCTTCCGTGCCTGAACACCTTTGG \\
rs737497 & CCCAAATCCAAACTCTGT & TCACTCCTGGCTGTCTAA \\
rs 1065411 & GCAGGAAACAAGGTAAAGG & AAGGAGGTAACGGAACAA \\
\hline
\end{tabular}

For PCR, made up standard PCR reaction mixture $(25 \mu \mathrm{L})$. Then, put the above mixture into Techne DNA thermal cycler (Biometra, Göttingen, Germany). The thermocycler protocol consisted of a 5 -min denaturation at $94^{\circ} \mathrm{C}, 30$ cycles of denaturation for $30 \mathrm{~s}$ at $94^{\circ} \mathrm{C}$, annealing for $30 \mathrm{~s}$ at $57.2^{\circ} \mathrm{C}(\mathrm{rs} 4891)$, $57.0^{\circ} \mathrm{C}(\mathrm{rs} 1695), 63.0^{\circ} \mathrm{C}(\mathrm{rs} 4630), 55.2^{\circ} \mathrm{C}(\mathrm{rs} 11550605), 52.0^{\circ}$ $\mathrm{C}$ (rs737497), or $53.0^{\circ} \mathrm{C}$ (rs1065411), and extension for $1 \mathrm{~min}$ at $72^{\circ} \mathrm{C}$, followed by a final single $10 \mathrm{~min}$ extension at $72^{\circ} \mathrm{C}$. The full-length PCR fragments were 368bp (rs4891), 502bp (rs1695), 402bp (rs4630), 247bp (rs11550605), 521bp (rs737497), and 262bp (rs1065411), respectively. The genotypes of rs4891C/T, and rs1695A/G SNPs were determined by RFLP analysis with the restriction endonuclease BaeGI and HpyCH4IV, respectively (New England Biolabs, Beijing, China). The lengths of restriction digest products were 103/ 265 bp for rs4891 C/T, and 233/289 bp for rs1695 A/G polymorphisms. The above products were all visualized by electrophoresis on $2 \%$ agarose gels and Genefounder ${ }^{\mathrm{TM}}$ staining (Bio-V, Xiamen, China).

\section{Statistical Analysis}

SPSS version 23.0 (SPSS, Chicago, IL, USA) was used for statistical analysis. Data are presented as mean $\pm \mathrm{SD}$, frequency, or percentage. Allele frequencies were calculated from the genotypes of all subjects. Chi-square test or Fisher's exact test was used to compare allele and genotype frequencies in patients and controls. Moreover, separate analyses by gender were carried out. All these tests were two-tailed, and the level of statistical significance was defined as $\mathrm{p}<0.05$.

\section{Results}

\section{GSTPI and SCZ}

In the healthy control group, the genotype distributions of the rs1695 A/G ( $\mathrm{p}=0.27,0.99)$ and $\mathrm{rs} 4891 \mathrm{C} / \mathrm{T}\left(\chi^{2}=0.22\right.$; $\mathrm{p}=0.89)$ polymorphisms showed no significant deviation from Hardy-Weinberg equilibrium. Therefore, the samples of the study were representative of the general north Han Chinese population. The genotype and allele distributions of the GSTP1 SNPs (rs1695 and rs4891) in schizophrenic patients and healthy controls are presented in Table 2. Neither genotype nor allele frequencies of the rs1695 A/G and rs4891 C/T polymorphisms differed significantly between patients and controls $\left(\chi 2=3.275, p=0.194 ; \chi^{2}=3.932, p=0.114\right)$. Moreover, no significant differences were observed for these two polymorphisms in dominant or recessive models. The genotype and allele frequencies of the two SNPs were then

Table 2 Genotype and Allele Distributions of GSTPI (RsI695 and Rs489I) in SCZ Patients and Controls

\begin{tabular}{|c|c|c|c|c|}
\hline SNP & Cases, $\mathrm{n}(\%)$ & Controls, n (\%) & $\chi^{2}$ & $\mathbf{p}$ \\
\hline \multicolumn{5}{|c|}{ rs1695A/G } \\
\hline \multicolumn{5}{|l|}{ Genotypes } \\
\hline AA & $227(60.2)$ & $270(65.1)$ & & \\
\hline AG & $140(37.1)$ & $130(31.3)$ & & \\
\hline GG & $10(2.7)$ & $15(3.6)$ & 3.275 & 0.194 \\
\hline \multicolumn{5}{|l|}{ Allele } \\
\hline A & $594(78.8)$ & $670(80.7)$ & & \\
\hline G & $160(21.2)$ & $160(19.3)$ & 0.463 & 0.496 \\
\hline \multicolumn{5}{|c|}{ Dominant Model a } \\
\hline AA & $227(60.2)$ & $270(65.1)$ & & \\
\hline$A G+G G$ & $150(39.8)$ & $145(34.9)$ & 1.986 & 0.159 \\
\hline \multicolumn{5}{|c|}{ Recessive Model b } \\
\hline GG & $10(2.7)$ & $15(3.6)$ & & \\
\hline$A G+A A$ & $367(97.3)$ & $400(96.4)$ & 0.598 & 0.439 \\
\hline \multicolumn{5}{|c|}{ rs489IT/C } \\
\hline \multicolumn{5}{|l|}{ Genotypes } \\
\hline TT & $211(57.8)$ & $267(64.3)$ & & \\
\hline $\mathrm{CT}$ & $138(37.8)$ & $129(31.1)$ & & \\
\hline $\mathrm{CC}$ & $16(4.4)$ & $19(4.6)$ & 3.932 & 0.114 \\
\hline \multicolumn{5}{|l|}{ Allele } \\
\hline$T$ & $560(76.7)$ & $664(80.0)$ & & \\
\hline C & $170(23.3)$ & $166(20.0)$ & 1.242 & 0.265 \\
\hline \multicolumn{5}{|c|}{ Dominant Model a } \\
\hline TT & $211(57.8)$ & $267(64.3)$ & & \\
\hline $\mathrm{TC}+\mathrm{CC}$ & $154(42.2)$ & $148(35.7)$ & 3.489 & 0.062 \\
\hline \multicolumn{5}{|c|}{ Recessive Model b } \\
\hline $\mathrm{CC}$ & $16(4.4)$ & $19(4.6)$ & & \\
\hline $\mathrm{TC}+\mathrm{TT}$ & $349(95.6)$ & $396(95.4)$ & 0.017 & 0.896 \\
\hline
\end{tabular}


compared between the patients and controls separated by gender (Table 3 ). There were no statistically significant differences detected between patients and controls in males or females for these two polymorphisms.

\section{GSTMI, GSTTI and SCZ}

The GSTM1 and GSTT1 genotype frequencies in schizophrenic patients and controls are shown in Table 4. The GSTT1 null distribution did not differ significantly between schizophrenic patients and controls $(\chi 2=0.690$, $\mathrm{p}=0.406)$. On the other hand, the GSTM1 null distribution was significantly different $(\chi 2=8.696, \mathrm{p}=0.003)$. The frequency of combined GSTM1 and GSTT1 alleles indicated that the double null alleles displayed significant differences between patients and controls. Other alleles (GSTM1+/GSTT1+, GSTM1+/GSTT1-, GSTM1-/GSTT1 + ) did not vary significantly between the two groups.
When analyzed separately by gender, the study yielded similar results (Table 5). The GSTM1 null genotype distribution differed significantly between patients and controls in both males and females analyzed separately $(\chi 2=$ 4.530, $\left.\mathrm{p}=0.033 ; \chi^{2}=4.253, \mathrm{p}=0.039\right)$. Combined GSTM1 and GSTT1 allele frequencies indicated that the double null alleles also maintained significant differences between patients and controls in both males and females.

\section{Discussion}

SCZ is a polygenic disease and many potential SCZ genes have been discovered in research. There are 1088 human genes in the SCZ gene database (http://www.szgene.org/) containing 8788 different polymorphisms, including the GST genes. Many studies have shown an increase in oxidative stress in patients with SCZ. ${ }^{29,30}$ Some scholars have found that with accumulation of oxides, the resulting

Table 3 Genotype and Allele Distributions of GSTPI (RsI695 and Rs489I) in SCZ Patients and Controls Separated by Sex

\begin{tabular}{|c|c|c|c|c|c|c|c|c|}
\hline SNP & $\begin{array}{l}\text { Male Cases, } \\
\text { n (\%) }\end{array}$ & $\begin{array}{l}\text { Male Controls, } \\
\text { n (\%) }\end{array}$ & $\chi^{2}$ & $\mathbf{p}$ & $\begin{array}{l}\text { Female Cases, } \\
\text { n (\%) }\end{array}$ & $\begin{array}{l}\text { Female Controls, } \\
\text { n (\%) }\end{array}$ & $\chi^{2}$ & $P$ \\
\hline \multicolumn{9}{|c|}{ rsl695A/G } \\
\hline \multicolumn{9}{|l|}{ Genotypes } \\
\hline AA & $116(60.7)$ & $140(65.7)$ & & & III(59.7) & $130(64.4)$ & & \\
\hline AG & $70(36.6)$ & $67(31.5)$ & & & $70(37.6)$ & $63(3 \mid .2)$ & & \\
\hline GG & $5(2.6)$ & $6(2.8)$ & 1.212 & 0.545 & $5(2.7)$ & $9(4.5)$ & 2.353 & 0.308 \\
\hline \multicolumn{9}{|l|}{ Allele } \\
\hline$A$ & $302(79.0)$ & $347(81.4)$ & & & $292(78.5)$ & $323(80.0)$ & & \\
\hline G & $80(21.0)$ & $79(18.6)$ & 0.733 & 0.392 & $80(21.5)$ & $8 I(20.0)$ & 0.250 & 0.617 \\
\hline \multicolumn{9}{|c|}{ Dominant Model a } \\
\hline $\mathrm{AA}$ & $116(60.7)$ & $140(65.7)$ & & & III(59.7) & $130(40.3)$ & & \\
\hline$A G+G G$ & $75(39.3)$ & $73(34.3)$ & 1.082 & 0.298 & $75(64.4)$ & $72(35.6)$ & 0.901 & 0.343 \\
\hline \multicolumn{9}{|c|}{ Recessive Model b } \\
\hline GG & $5(2.6)$ & $6(2.8)$ & & & $5(2.7)$ & $9(4.5)$ & & \\
\hline$A G+A A$ & 186(97.4) & $207(97.2)$ & 0.015 & 0.902 & I8I(97.3) & $193(95.5)$ & 0.870 & 0.351 \\
\hline \multicolumn{9}{|l|}{ rs489 IT/C } \\
\hline \multicolumn{9}{|l|}{ Genotypes } \\
\hline $\mathrm{TT}$ & $108(58.4)$ & $136(63.8)$ & & & $103(57.2)$ & $|3|(64.9)$ & & \\
\hline $\mathrm{CT}$ & $68(36.8)$ & $67(31.5)$ & & & $70(38.9)$ & $62(30.7)$ & & \\
\hline $\mathrm{CC}$ & $9(4.9)$ & $10(4.7)$ & 1.310 & 0.519 & $7(3.9)$ & $9(4.5)$ & 2.828 & 0.247 \\
\hline \multicolumn{9}{|l|}{ Allele } \\
\hline $\mathrm{T}$ & $284(76.8)$ & $339(79.6)$ & & & $276(76.7)$ & $324(80.2)$ & & \\
\hline C & $86(23.2)$ & $87(20.4)$ & 0.926 & 0.336 & $84(23.3)$ & $80(19.8)$ & 1.408 & 0.235 \\
\hline \multicolumn{9}{|c|}{ Dominant Model a } \\
\hline $\mathrm{TT}$ & $108(58.4)$ & $136(63.8)$ & & & $103(57.2)$ & $|3|(64.9)$ & & \\
\hline $\mathrm{TC}+\mathrm{CC}$ & $77(4 \mid .6)$ & $77(36.2)$ & 1.249 & 0.264 & $77(42.8)$ & $7 I(35.1)$ & 2.334 & 0.127 \\
\hline \multicolumn{9}{|c|}{ Recessive Model b } \\
\hline $\mathrm{CC}$ & $9(4.9)$ & $10(4.7)$ & & & $7(3.9)$ & $9(96.1)$ & & \\
\hline $\mathrm{TC}+\mathrm{TT}$ & $176(95.1)$ & $203(95.3)$ & 0.006 & 0.937 & $173(4.5)$ & $193(95.5)$ & 0.076 & 0.783 \\
\hline
\end{tabular}


Table 4 Distribution of Genotype Frequencies of GSTMI and GSTTI in SCZ Patients and Controls

\begin{tabular}{|c|c|c|c|c|}
\hline GST Genotype & Cases, n (\%) & Controls, n (\%) & $\chi^{2}$ & $\boldsymbol{P}$ \\
\hline \multicolumn{5}{|l|}{ GSTTI Deletion } \\
\hline Deletion based on both GSTTI SNPs & $158(4 \mid .7)$ & $16 \mathrm{I}(38.8)$ & 0.690 & 0.406 \\
\hline Deletion based on rs 4630 & $179(47.2)$ & I82(43.9) & 0.910 & 0.340 \\
\hline Deletion based on rsII550605 & $167(44.1)$ & 194(46.7) & 0.575 & 0.448 \\
\hline \multicolumn{5}{|l|}{ GSTMI Deletion } \\
\hline Deletion based on both GSTMI SNPs & $177(46.7)$ & $|5|(36.4)$ & 8.696 & $0.003 *$ \\
\hline Deletion based on rs737497 & $198(52.2)$ & $174(41.9)$ & 8.464 & $0.004 *$ \\
\hline Deletion based on rs $106541 \mathrm{I}$ & $214(56.5)$ & $192(46.3)$ & 8.247 & $0.004 *$ \\
\hline \multicolumn{5}{|l|}{ Combined } \\
\hline GSTMI+/GSTTI+ & $153(40.4)$ & I86(44.8) & & \\
\hline GSTMI+/GSTTI- & $49(12.9)$ & $78(18.8)$ & & \\
\hline GSTMI-/GSTTI+ & $68(17.9)$ & $68(16.4)$ & & \\
\hline GSTMI-/GSTTI- & $109(28.8)$ & $83(20.0)$ & 11.747 & $0.008 *$ \\
\hline
\end{tabular}

Note: $* P<0.05$.

Table 5 Distribution of Genotype Frequencies of GSTMI and GSTTI in SCZ Patients and Controls Separated by Sex

\begin{tabular}{|c|c|c|c|c|c|c|c|c|}
\hline GST Genotype & $\begin{array}{l}\text { Male Cases, } \\
\text { n (\%) }\end{array}$ & $\begin{array}{l}\text { Male Controls, } \\
\text { n (\%) }\end{array}$ & $\chi^{2}$ & $\mathbf{p}$ & $\begin{array}{l}\text { Female Cases, } \\
\text { n (\%) }\end{array}$ & $\begin{array}{l}\text { Female Controls, } \\
\text { n (\%) }\end{array}$ & $\chi^{2}$ & $\mathbf{P}$ \\
\hline \multicolumn{9}{|l|}{ GSTTI Deletion } \\
\hline Deletion based on both GSTTI & $82(42.7)$ & $83(39.0)$ & 0.585 & 0.444 & $76(40.6)$ & $78(38.6)$ & 0.167 & 0.683 \\
\hline SNPs & & & & & & & & \\
\hline Deletion based on rs 4630 & $95(49.5)$ & $87(43.5)$ & 1.485 & 0.223 & $84(44.9)$ & $95(47.0)$ & 0.174 & 0.677 \\
\hline Deletion based on rsII550605 & $88(45.8)$ & $103(48.4)$ & 0.258 & 0.611 & $88(42.2)$ & $103(45.0)$ & 0.310 & 0.578 \\
\hline \multicolumn{9}{|l|}{ GSTMI Deletion } \\
\hline Deletion based on both GSTMI & $95(49.5)$ & $83(39.0)$ & 4.530 & 0.033 & $82(43.9)$ & $68(33.7)$ & 4.253 & $0.039 *$ \\
\hline \multicolumn{9}{|l|}{ SNPs } \\
\hline Deletion based on rs 737497 & $103(53.6)$ & $92(43.2)$ & 4.420 & 0.036 & $95(50.8)$ & $82(40.6)$ & 4.081 & 0.043 \\
\hline Deletion based on rs $106541 \mathrm{I}$ & $110(57.3)$ & $100(46.9)$ & 4.327 & 0.038 & 104(55.6) & $92(45.5)$ & 3.939 & $0.047^{*}$ \\
\hline \multicolumn{9}{|l|}{ Combined } \\
\hline GSTMI+/GSTTI+ & $74(38.5)$ & $85(39.9)$ & & & $79(42.2)$ & $88(43.6)$ & & \\
\hline GSTMI+/GSTTI- & $23(12.0)$ & $45(21.1)$ & & & $26(13.9)$ & $46(22.8)$ & & \\
\hline GSTMI-/GSTTI+ & $36(18.8)$ & $45(21.1)$ & & & $32(17.1)$ & $36(17.8)$ & & \\
\hline GSTMI-/GSTTI- & $59(30.7)$ & $38(17.8)$ & 12.369 & 0.006 & $50(26.7)$ & $32(15.8)$ & 9.663 & $0.022^{*}$ \\
\hline
\end{tabular}

Note: $* P<0.05$.

catecholamine o-quinones can cause dopaminergic neuron degeneration. ${ }^{31}$ GSTs exert their antioxidant function by degrading the oxidative metabolite of catecholamine o-quinones. ${ }^{19}$ GSTs can also work synergistically with other proteins to detoxify neurotoxic substances, such as aldehydes produced by membrane lipid peroxidation, and protect nerve cells from damage. Furthermore, GST is a key enzyme in the GSH binding reaction, which can catalyze the binding of GSH with bioactive intermediates that may cause damage to the body, thereby preventing damage to the body, and consequently protecting nerve cells from oxidative stress. ${ }^{28}$

In addition to the above mechanism, GSTP plays a regulatory role in signaling by regulation of variable kinases. ${ }^{32}$ Our study did not find an association of SCZ with either GSTP1 SNP (rs1695 or rs4891), consistent with the findings of other scholars. ${ }^{33}$ These studies concluded that the GSTP1 SNP genotype was not associated with the Positive Negative Symptoms Scale (PANSS) for SCZ, the Brief Psychiatric Rating Scale (BPRS), the 
number of admissions, or the age at onset. These findings also suggest that the GSTP1 polymorphism may not increase the susceptibility to SCZ in Koreans, ${ }^{28}$ however, they did not completely rule it out, as other studies have concluded that GSTP1 (rs1695 AG, AG+GG) does increase the risk of SCZ in Koreans. ${ }^{26}$ Schizophrenia is related to oxidative stress. Many studies found that the level of oxidative stress was different between men and women, mainly manifested by higher levels of oxidative stress in women. ${ }^{34-36}$ This conclusion is consistent with the gender differences that have been identified so far, that is, the prevalence of female schizophrenia is higher than that of males. Some studies found that oxidative stress levels increase in women with schizophrenia. ${ }^{36}$ But gender differences in oxidative stress have not been fully studied in patients with schizophrenia. Therefore, this study classified genetic polymorphisms by sex. However, no significant difference was found in the GSTP1 genotype in both male and female patients. The results of this study are consistent with those of Tripathi S and Bănescu C. ${ }^{37,38}$ It is further shown that the GSTP1 gene polymorphism has nothing to do with schizophrenia in Chinese Han population. SCZ is a polygenic hereditary disease, and GSTP1 is characterized by uneven ethnic distribution, further clouding the relationship between GSTP1 and SCZ. The relationship between GSTP1 and SCZ still needs to be confirmed in larger research samples.

In recent years, researchers have tested GSTM1 and GSTT1 gene deletion rates in a variety of populations. According to reports in the literature, the American GSTM1 gene deletion rate is $23-62 \%$, Europeans $39-62 \%$, Africans $23-48 \%$, and Asians $33-63 \% .{ }^{39}$ The GSTT1 gene deletion rate is roughly $22-31 \%$ for Americans, $10-21 \%$ for Europeans, $15-26 \%$ for Africans, and $16-64 \%$ for Asians. ${ }^{39}$ The GSTM1 and GSTT1 gene deletion rates are extensively regional and racially diverse, which may be due to differences in exposure to geographic differences, environment, and diet. Our results show that the gene deletion rate of GSTM1 is $36.4 \%$, consistent with the above results. And our study found that GSTM polymorphisms are associated with SCZ. Our results are consistent with the findings of several researchers, but are inconsistent with others. ${ }^{40-43}$ Studies by Raffa and Gravina concluded that there was no association between GSTM1 genotype and SCZ. ${ }^{19,27}$ However, it is possible that the inconsistency of these studies is related to the differences in study populations. Additionally, a meta-analysis showed that GSTM1 polymorphisms were not associated with risk of SCZ without racial differentiation, but analysis of ethnicity indicated that the GSTM1 polymorphism may be a genetic risk factor for SCZ in East Asian populations. ${ }^{40}$ A Study pointed out that the gender gap between GSTM1 null genotypes was significant. ${ }^{37}$ Therefore, this study also explored the relationship between the frequency of GSTM1 genotypes of different genders and schizophrenia. When gender was taken into account, the result remained that GSTM polymorphisms were related to SCZ. Our study suggested that the GSTM1 gene polymorphism was one of the risk indicators for SCZ, but whether it will be useful as a biomarker for SCZ in the East Asian population still requires further exploration in larger samples and multiple regions. Our results show that the gene deletion rate of GSTT1 is $38.8 \%$, consistent with the results of other studies. We also show that the GSTT1 SNP is not associated with SCZ, consistent with the findings of Matsuzawa et $\mathrm{al}^{44}$. On the other hand, a different study by Kashani et al found that the GSTT1-null genotype significantly increased the risk of SCZ and that GSTT1 is a susceptibility candidate for SCZ. ${ }^{26}$ But the results of Saadat et al do not support any of the above observations. ${ }^{45}$ Saadat and colleagues found that the GSTT1-null genotype was inversely related to SCZ, and the GSTT1-null was protective against SCZ. Therefore, they proposed that GSTT1 activity is implicated in SCZ susceptibility and GSTT1 genotype is a candidate gene for susceptibility to SCZ. These findings suggested that the ancestral GSTT1 had dehalogenase activity on several halogenated compounds. ${ }^{46}$ When used as a metabolic activator of halogenated compounds, it could produce a variety of intermediates that are potentially hazardous to DNA and cells. ${ }^{46}$ In contrast, we found that although GSTT1 may produce some harmful substances in the metabolic reaction of halogenated compounds, its antioxidant effect may have a greater impact on the organism. This result supported the conclusion of Kim et $\mathrm{al}^{40}$. In addition, the study also concluded that there was no difference in genotype frequency among patients stratified by gender. It further confirms that in the northern Han population, GSTT1 has better antioxidant effect in vivo than dehalogenation, but has nothing to do with SCZ.

It is well known that the genetics of SCZ are complex and the result of interactions between multiple genes. Therefore, we also examined the relationship between the interaction of GSTT1 and GSTM1 with SCZ. We found that there were significant differences in the double null allele 
frequencies between patients and controls. In addition, the results did not change after sex grouping. The results further confirm that oxidative stress is associated with the onset of SCZ. As Mico et al concluded, patients with severe and chronic diseases, such as SCZ and bipolar disorder, have higher oxidative stress markers. ${ }^{47}$ In addition, Pinheiro et al showed that the double null genotype (GSTT1-null /GSTM1-null) was significantly associated with the development of SCZ; this combined genotype resulted in a 4.6-fold increased risk of developing SCZ. ${ }^{48}$ This result was consistent with the complex genetic theory of SCZ, highlighting the effects of several genetic interactions and suggested that the combination of GST polymorphisms may play a role in susceptibility to SCZ. ${ }^{49}$ As Milica et al said, we can understand the relationship between GST polymorphism and SCZ from the perspective of vascular injury. ${ }^{50}$ Because oxidative stress may mediate vascular damage in the body, studies have determined that patients with mental illnesses are also at higher risk for cardiovascular disease and diabetes. ${ }^{18}$ The null genotypes of GSTM1 and GSTT1 have been shown to increase susceptibility for cardiovascular disease. ${ }^{51}$ This study showed that GSTM1 and GSTT1 double null genotypes were associated with schizophrenia in both men and women, but the difference between the male case group and the control group was more significant. This conclusion can be better explained from a cardiovascular perspective, as men are at higher risk for cardiovascular disease.

\section{Conclusion}

The GSTM1 null genotype and the GSTM1 and GSTT1 double null genotype may be related to the onset of SCZ in Chinese Han population.

\section{Acknowledgments}

This work was supported by grants from the Major Project of the Department of Science and Technology of Liaoning Province (2019JH8/10300019). We thank all the volunteers for participating in this study.

\section{Disclosure}

All authors declare that they have no conflicts of interest in this work.

\section{References}

1. Tandon R, Gaebel W, Barch DM, et al. Definition and description of schizophrenia in the DSM-5. Schizophr Res. 2013;150:3-10. doi:10. 1016/j.schres.2013.05.028
2. Lloyd J, Lloyd H, Fitzpatrick R, et al. Treatment outcomes in schizophrenia: qualitative study of the views of family carers. $B M C$ Psychiatry. 2017;17:266. doi:10.1186/s12888-017-1418-8

3. Phillips MR, Zhang J, Shi Q, et al. Prevalence, treatment, and associated disability of mental disorders in four provinces in China during 2001-05: an epidemiological survey. Lancet. 2009;373:2041-2053. doi:10.1016/ S0140-6736(09)60660-7

4. Moran P, Stokes J, Marr J, et al. Gene Environment interactions in schizophrenia: evidence from genetic mouse models. Neural Plast. 2016;2016:2173748. doi:10.1155/2016/2173748

5. Nimgaonkar VL, Prasad KM, Chowdari KV, et al. The complement system: a gateway to gene-environment interactions in schizophrenia pathogenesis. Mol Psychiatry. 2017;22:1554-1561. doi:10.1038/ mp.2017.151

6. Tuncel OK, Sarisoy G, Bilgici B, et al. Oxidative stress in bipolar and schizophrenia patients. Psychiatry Res. 2015;228:688-694. doi:10.1016/j.psychres.2015.04.046

7. Wadhwa R, Gupta R, Maurya PK. Oxidative stress and accelerated aging in neurodegenerative and neuropsychiatric disorder. Curr Pharm Des. 2018;24:4711-4725. doi:10.2174/138161282566619011 5121018

8. Bai ZL, Li XS, Chen GY, et al. Serum oxidative stress marker levels in unmedicated and medicated patients with schizophrenia. $J \mathrm{Mol}$ Neurosci. 2018;66:428-436. doi:10.1007/s12031-018-1165-4

9. Lleo A, Parnetti L, Belbin O, et al. Has the time arrived for cerebrospinal fluid biomarkers in psychiatric disorders? Clin Chim Acta. 2019;491:81-84. doi:10.1016/j.cca.2019.01.019

10. Prabakaran S, Wengenroth M, Lockstone HE, et al. 2-D DIGE analysis of liver and red blood cells provides further evidence for oxidative stress in schizophrenia. J Proteome Res. 2007;6:141-149. doi:10.1021/pr060308a

11. Dietrich-Muszalska A, Olas B, Rabe-Jablonska J. Oxidative stress in blood platelets from schizophrenic patients. Platelets. 2005;16:386-391. doi:10.1080/09537100500128872

12. Sirota P, Gavrieli R, Wolach B. Overproduction of neutrophil radical oxygen species correlates with negative symptoms in schizophrenic patients: parallel studies on neutrophil chemotaxis, superoxide production and bactericidal activity. Psychiatry Res. 2003;121:123-132. doi:10.1016/S0165-1781(03)00222-1

13. Bitanihirwe BK, Woo TU. Oxidative stress in schizophrenia: an integrated approach. Neurosci Biobehav Rev. 2011;35:878-893. doi:10.1016/j.neubiorev.2010.10.008

14. Flatow J, Buckley P, Miller BJ. Meta-analysis of oxidative stress in schizophrenia. Biol Psychiatry. 2013;74:400-409. doi:10.1016/j. biopsych.2013.03.018

15. Chowdari KV, Bamne MN, Nimgaonkar VL. Genetic association studies of antioxidant pathway genes and schizophrenia. Antioxid Redox Signal. 2011;15:2037-2045. doi:10.1089/ars.2010.3508

16. Mannervik B, Awasthi YC, Board PG, et al. Nomenclature for human glutathione transferases. Biochem J. 1992;282:305-306. doi:10.1042/ bj 2820305

17. Gawryluk JW, Wang JF, Andreazza AC, et al. Prefrontal cortex glutathione S-transferase levels in patients with bipolar disorder, major depression and schizophrenia. Int J Neuropsychopharmacol. 2011;14:1069-1074. doi:10.1017/S1461145711000617

18. Do KQ, Trabesinger AH, Kirsten-Kruger M, et al. Schizophrenia: glutathione deficit in cerebrospinal fluid and prefrontal cortex in vivo. Eur J Neurosci. 2000;12:3721-3728. doi:10.1046/j.1460-9568.2000.00229.x

19. Gravina P, Spoletini I, Masini S, et al. Genetic polymorphisms of glutathione S-transferases GSTM1, GSTT1, GSTP1 and GSTA1 as risk factors for schizophrenia. Psychiatry Res. 2011;187:454-456. doi:10.1016/j.psychres.2010.10.008

20. Malik MA, Gupta V, Shukla S, et al. Glutathione S-transferase (GSTM1, GSTT1) polymorphisms and JOAG susceptibility: a case control study and meta-analysis in glaucoma. Gene. 2017;628:246-252. doi:10.1016/ j.gene.2017.07.028 
21. Ding Z, Wang K, Li J. Association between glutathione S-transferase gene M1 and T1 polymorphisms and chronic obstructive pulmonary disease risk: a meta-analysis. Clin Genet. 2019;95:53-62. doi: $10.1111 /$ cge. 13373

22. Hashimoto T, Hashimoto K, Matsuzawa D, et al. A functional glutathione S-transferase P1 gene polymorphism is associated with methamphetamine-induced psychosis in Japanese population. $A m$ J Med Genet B Neuropsychiatr Genet. 2005;135b:5-9. doi:10.1002/ (ISSN) 1552-485X

23. Tsuchida S, Sato K. Glutathione transferases and cancer. Crit Rev Biochem Mol Biol. 1992;27:337-384. doi:10.3109/10409239 209082566

24. Nebert DW, Vasiliou V. Analysis of the glutathione S-transferase (GST) gene family. Hum Genomics. 2004;1:460-464. doi:10.1186/ 1479-7364-1-6-460

25. Rostami G, Assad D, Ghadyani F, et al. Influence of glutathione S-transferases (GSTM1, GSTT1, and GSTP1) genetic polymorphisms and smoking on susceptibility risk of chronic myeloid leukemia and treatment response. Mol Genet Genomic Med. 2019;7:e0717.

26. Kashani FL, Kordi-Tamandani DM, Sahranavard R, et al. Analysis of glutathione S-transferase genes polymorphisms and the risk of schizophrenia in a sample of Iranian population. Neuron Glia Biol. 2011;7:199-203. doi:10.1017/S1740925X12000130

27. Raffa M, Lakhdar R, Ghachem M, et al. Relationship between GSTM1 and GSTT1 polymorphisms and schizophrenia: a case-control study in a Tunisian population. Gene. 2013;512:282-285. doi:10.1016/j.gene.2012.10.031

28. Pae CU, Kim JJ, Lee SJ, et al. Association study between glutathione S-transferase P1 polymorphism and schizophrenia in the Korean population. Prog Neuropsychopharmacol Biol Psychiatry. 2003;27:519-523. doi:10.1016/S0278-5846(03)00043-5

29. Reyazuddin M, Azmi SA, Islam N, et al. Oxidative stress and level of antioxidant enzymes in drug-naive schizophrenics. Indian J Psychiatry. 2014;56:344-349. doi:10.4103/0019-5545.146516

30. Dogan HO, Ersan EE, Aydin H, et al. Thiol disulfide homeostasis in schizophrenic patients using atypical antipsychotic drugs. Clin Psychopharmacol Neurosci. 2018;16:39-45. doi:10.9758/cpn.2018. 16.1.39

31. Yao JK, Reddy R, McElhinny LG, et al. Reduced status of plasma total antioxidant capacity in schizophrenia. Schizophr Res. 1998;32:1-8. doi:10.1016/S0920-9964(98)00030-9

32. Duman RS, Heninger GR, Nestler EJ. Molecular psychiatry. Adaptations of receptor-coupled signal transduction pathways underlying stress- and drug-induced neural plasticity. J Nerv Ment Dis. 1994;182:692-700. doi:10.1097/00005053-199412000-00003

33. Gao H, Liu C, Song S, et al. GPX1 Pro198Leu polymorphism and GSTP1 Ile105Val polymorphisms are not associated with the risk of schizophrenia in the Chinese Han population. Neuroreport. 2017;28:969-972. doi:10.1097/WNR.0000000000000870

34. Abdelkrim K, Ali T, Sina K, et al. Gender-specific association of oxidative stress and inflammation with cardiovascular risk factors in Arab population. Mediators Inflamm. 2015;2015:1-11.

35. Peskind ER, Li G, Shofer JB, et al. Influence of lifestyle modifications on age-related free radical injury to brain. JAMA Neurol. 2014;71:1150. doi:10.1001/jamaneurol.2014.1428

36. Lee EE, Eyler LT, Wolkowitz OM, et al. Elevated plasma F2-isoprostane levels in schizophrenia. Schizophr Res. 2016; S092099641630278X.
37. Tripathi S, Ghoshal U, Ghoshal UC, et al. Gastric carcinogenesis: possible role of polymorphisms of GSTM1, GSTT1, and GSTP1 genes. Scand $J$ Gastroenterol. 2008;43:431-439. doi:10.1080/ 00365520701742930

38. Bănescu C, Iancu M, Trifa AP. et al. From Six gene polymorphisms of the antioxidant system, only GPX Pro198Leu and GSTP1 Ile105Val modulate the risk of acute myeloid leukemia. Oxid Med Cell Longev;2016. 1-10. doi:10.1155/2016/2536705

39. Ramos Hernandez C, Mouronte-Roibas C, Barros-Dios JM, et al. Deletion of GSTM1 and GSTT1 genes and lung cancer survival: a systematic review. Tumori. 2017;103:338-344. doi:10.5301/ tj.5000621

40. Kim SK, Kang SW, Chung JH, et al. Genetic polymorphisms of glutathione-related enzymes (GSTM1, GSTT1, and GSTP1) and schizophrenia risk: a meta-analysis. Int $J$ Mol Sci. 2015;16:19602-19611. doi:10.3390/ijms160819602

41. Watanabe Y, Nunokawa A, Kaneko N, et al. A case-control study and meta-analysis of association between a common copy number variation of the glutathione S-transferase mu 1 (GSTM1) gene and schizophrenia. Schizophr Res. 2010;124:236-237. doi:10.1016/j. schres.2010.08.001

42. Harada S, Tachikawa H, Kawanishi Y. Glutathione S-transferase M1 gene deletion may be associated with susceptibility to certain forms of schizophrenia. Biochem Biophys Res Commun. 2001;281:267-271. doi:10.1006/bbrc. 2001.4347

43. Marik PE, Vasu T, Hirani A, et al. Stress ulcer prophylaxis in the new millennium: a systematic review and meta-analysis. Crit Care Med. 2010;38:2222-2228. doi:10.1097/CCM.0b013e3181f17adf

44. Matsuzawa D, Hashimoto K, Hashimoto T, et al. Association study between the genetic polymorphisms of glutathione-related enzymes and schizophrenia in a Japanese population. Am J Med Genet B Neuropsychiatr Genet. 2009;150b:86-94. doi:10.1002/ajmg.b. v150b:1

45. Saadat M, Mobayen F, Farrashbandi H. Genetic polymorphism of glutathione S-transferase T1: a candidate genetic modifier of individual susceptibility to schizophrenia. Psychiatry Res. 2007;153:87-91. doi: $10.1016 /$ j.psychres.2006.03.024

46. Landi S. Mammalian class theta GST and differential susceptibility to carcinogens: a review. Mutat Res-Rev Mutat. 2000;463:247-283. doi:10.1016/S1383-5742(00)00050-8

47. Mico JA, Rojas-Corrales MO, Gibert-Rahola J, et al. Reduced antioxidant defense in early onset first-episode psychosis: a case-control study. BMC Psychiatry. 2011;11:26. doi:10.1186/1471-244X-11-26

48. Pinheiro DS, Santos RDS, de Brito RB, et al. GSTM1/GSTT1 double-null genotype increases risk of treatment-resistant schizophrenia: a genetic association study in Brazilian patients. PLoS One. 2017;12:e0183812. doi:10.1371/journal.pone.0183812

49. Sullivan PF, Kendler KS, Neale MC. Schizophrenia as a complex trait: evidence from a meta-analysis of twin studies. Arch Gen Psychiatry. 2003;60:1187-1192. doi:10.1001/archpsyc.60.12.1187

50. Milica M, Vanja D, Vesna M. Glutathione S-transferase deletion polymorphisms in early-onset psychotic and bipolar disorders: a case-control study. Lab Med. 2016;47:1-10.

51. Ramprasath T, Senthil Murugan P, Prabakaran AD, et al. Potential risk modifications of GSTT1, GSTM1 and GSTP1 (glutathione-S-transferases) variants and their association to CAD in patients with type-2 diabetes. Biochem Biophys Res Commun. 2011;407:49-53. doi:10.1016/j.bbrc.2011.02.097 


\section{Publish your work in this journal}

Neuropsychiatric Disease and Treatment is an international, peerreviewed journal of clinical therapeutics and pharmacology focusing on concise rapid reporting of clinical or pre-clinical studies on a range of neuropsychiatric and neurological disorders. This journal is indexed on PubMed Central, the 'PsycINFO' database and CAS, and is the official journal of The International Neuropsychiatric Association (INA). The manuscript management system is completely online and includes a very quick and fair peer-review system, which is all easy to use. Visit http://www.dovepress.com/testimonials.php to read real quotes from published authors.

Submit your manuscript here: https://www.dovepress.com/neuropsychiatric-disease-and-treatment-journal 